\title{
ARTICLE OPEN \\ Impact of alkali on the passivation of silicate glass
}

\author{
Marie Collin ${ }^{1}$, Maxime Fournier $\mathbb{D}^{1}$, Thibault Charpentier $\mathbb{D}^{2}$, Mélanie Moskura ${ }^{2}$ and Stéphane Gin ${ }^{1}$
}

Amorphous silica-rich surface layers, also called gels, can passivate silicate glass and minerals depending on environmental conditions. However, several uncertainties remain on the mechanisms controlling the formation of these layers. In this paper, the influence of exogenous ions supplied by solutions is studied, both on the formation and on the properties of the gel formed on international simple glass (ISG). ISG was altered at $90^{\circ} \mathrm{C}, \mathrm{pH}_{90}{ }^{\circ} \mathrm{C} 7$, in silica-saturated solutions containing various alkaline cations separately $\left(\mathrm{Li}^{+}, \mathrm{Na}^{+}, \mathrm{K}^{+}\right.$, and $\left.\mathrm{Cs}^{+}\right)$. The alteration kinetics observed with $\mathrm{Li}$ and $\mathrm{Na}$ in the solution is similar to that observed with no ions, while $\mathrm{K}$ and $\mathrm{Cs}$ in the solution tend to decrease glass alteration. Furthermore, for $\mathrm{K}$ or $\mathrm{Cs}$ ions, the kinetics decreases as the ionic strength of the solution increases. The passivation layer formed in these solutions shows a selectivity toward cations following the series $\mathrm{K}>\mathrm{Cs}>\mathrm{Na}>>\mathrm{Li}$. These alkalis replace $\mathrm{Ca}$ from pristine glass in the altered structures, leading to differences in $\left[\mathrm{AlO}_{4}\right]^{-}$ units charge compensation. Importantly, exchange between $\mathrm{Ca}$ and alkali also affects the total quantity of water inside each gel and this effect is well correlated with the observed drop in glass alteration.

npj Materials Degradation (2018)2:16; doi:10.1038/s41529-018-0036-3

\section{INTRODUCTION}

The current French approach for high-level waste storage is by incorporating radionuclides inside a borosilicate glass matrix. Subsequently, these glass canisters will be stored in a deep geological formation. ${ }^{1}$ However, ground water will eventually reach the glass after corrosion or diffusion through the different barriers. It is well known that glass, when in contact with water, goes through major structural and chemical changes, which need to be thoroughly understood. ${ }^{2-5}$

Glass alteration mechanisms are still heavily debated inside the scientific community, as no consensus has been reached yet for the way the passivation layer forms on the glass surface. ${ }^{6-9}$ To better understand glass alteration at high reaction progress, Gin, et al. $^{10}$ and Collin, et al. ${ }^{11}$ performed studies in Si-saturated conditions and slightly alkaline $\mathrm{pH}$ conditions, and characterized the passivating material. In these specific conditions, $\mathrm{B}, \mathrm{Na}$, and to a lesser extent $\mathrm{Ca}$ are leached out. $\mathrm{Zr}$ and $\mathrm{Al}$ are not released into the solution, and no exchange is observed between ${ }^{29} \mathrm{Si}$ from the solution and ${ }^{28} \mathrm{Si}$ of the network. This supports the idea that the remaining network formers are not completely hydrolyzed, and partly re-condense after B dissolution to form a porous gel layer.

However, differences arose between these studies, mainly concerning mobile element diffusion and altered glass quantities. The only significant variance between both studies is the concentration of $\mathrm{K}$ in the solution $\left(>80 \mathrm{mmol} \mathrm{L}^{-1}\right.$ for Gin, et al. ${ }^{10}$ vs $<1 \mathrm{mmol} \mathrm{L}^{-1}$ for Collin, et al. ${ }^{11}$ ). This raises the question on the effect of alkalis on glass alteration in Si-saturated solutions. It is well known that alkalis affect the alteration of minerals ${ }^{12-14}$ and glasses ${ }^{15,16}$ in the first stage of corrosion (highly diluted conditions leading to network hydrolysis). The presence of alkalis in solution enhances both quartz and nuclear glass dissolution. ${ }^{12-15}$ Jollivet, et al. ${ }^{15}$ suggested that this could be due to interactions between cations and deprotonated hydroxyls $\left(-X-\mathrm{O}^{-}\right.$where $X=\mathrm{Si}, \mathrm{Al}$ or $\mathrm{Zr}$ ). These interactions could weaken $\mathrm{Si}-\mathrm{O}$ bonds of the network, which could in turn facilitate network dissolution. However, at higher reaction progress, i.e. in conditions close to saturation, network hydrolysis is not the rate-limiting mechanism anymore, ${ }^{17,18}$ yet the effect of alkalis on glass alteration in those conditions has not been studied.

In the present study, the effect of $\mathrm{Li}, \mathrm{Na}, \mathrm{K}$, and $\mathrm{Cs}$ on glass alteration in Si-saturated conditions, $90^{\circ} \mathrm{C}, \mathrm{pH}_{90}{ }^{\circ} \mathrm{C}$, was studied. In these conditions, a significant drop in alteration kinetics occurred when $\mathrm{K}$ or Cs were introduced in the solution. However, the drop in the kinetics was gradual as the ionic strength was increased. To explain the differences in alteration kinetics depending on the alkali in the solution, altered materials, here called gels, were characterized. Their chemical compositions were determined, highlighting a higher selectivity of the gel for $\mathrm{K}$ and $\mathrm{Cs}$ than for $\mathrm{Na}$ and $\mathrm{Li}$. Gel structures were then examined using solid-state nuclear magnetic resonance (NMR) spectroscopy. No significant structure variations were observed, except on $\left[\mathrm{AlO}_{4}\right]^{-}$ units charge compensation. Finally, water quantity and speciation were determined in each gel by combining thermogravimetric analysis (TGA) and ${ }^{1} \mathrm{H}$ NMR, showing a decrease in water amount when the concentration of alkali increased. The drop in alteration rate could therefore be a consequence of the gel selectivity for larger cations that could reduce water accessibility to the pristine material. This raises interesting question regarding the upgrade of nuclear waste safe storage.

\section{RESULTS}

Alteration kinetics

ISG glass powders of $20-40 \mu \mathrm{m}$ in particle size were altered at $90^{\circ}$ $\mathrm{C}, \mathrm{pH} 90^{\circ} \mathrm{C} 7$ in Si-saturated conditions with alkali introduced separately in the solution $(\mathrm{LiCl}, \mathrm{KCl}$ and $\mathrm{CsCl}$ with concentrations ranging from 0 to $70 \mathrm{mmol} \mathrm{L}^{-1}$ and $\mathrm{NaCl}$ with a concentration of $20 \mathrm{mmol} \mathrm{L}^{-1}$ : as $\mathrm{Na}$ is present in pristine glass, only one concentration was studied to compare with other alkali). For all experiments, the $\mathrm{Si}$ concentration remained stable over time, 
while $\mathrm{Zr}$ and $\mathrm{Al}$ concentrations stayed under the detection limit $(0.10 \mathrm{ppm})$. For a similar concentration in alkali $\left(20 \mathrm{mmol} \mathrm{L}^{-1}\right), \mathrm{B}-$ used as glass alteration tracer-displays different behaviors (Fig. 1a) depending on the cation present in solution. While the glass alteration kinetics in the $\mathrm{Li}$ - and $\mathrm{Na}$-solutions is quite similar to that observed in the no alkali-solution, a significant drop is observed for $K$ - and Cs-solutions. Additionally, the equivalent thickness ET(B) is well correlated with $t^{1 / 2}$ in $\mathrm{Li}$-, $\mathrm{Na}$ - and no alkali-solutions (Fig. $1 \mathrm{~b})$ up to 130 days. This could indicate that diffusion of some

(a)

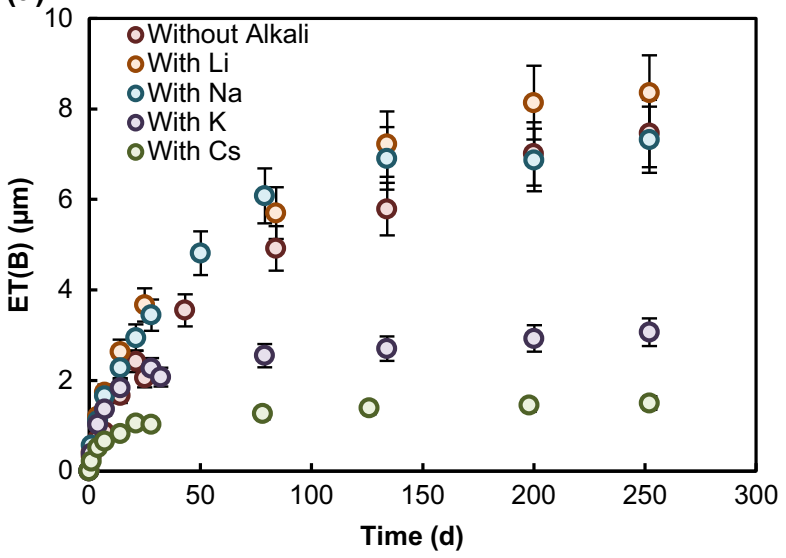

(c)

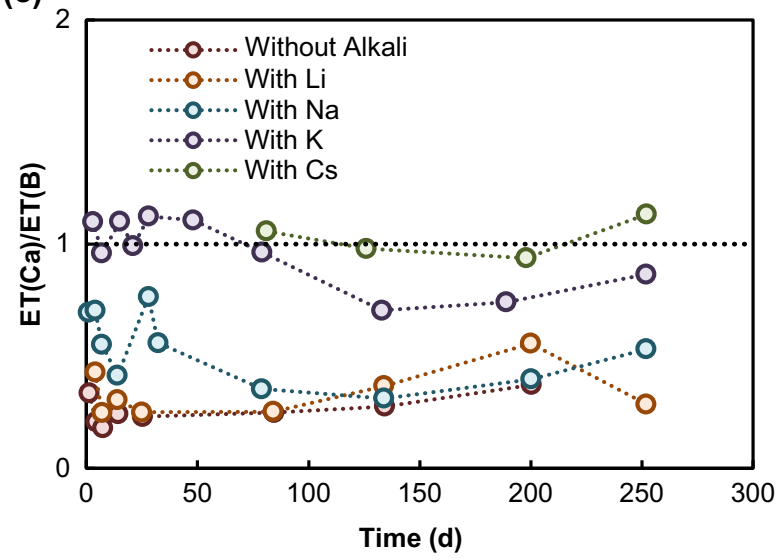

(e)

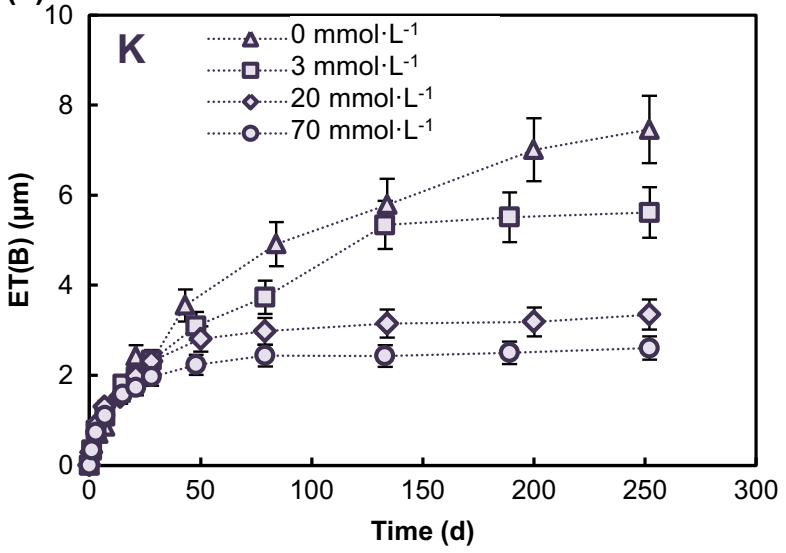

reactive species through the growing gel is rate-limiting during this first period. The glass alteration kinetics appears to leave this square root of time tendency after 130 days in the $\mathrm{Li}$ - and $\mathrm{Na}$ solutions. However, the model used to calculate the ET(B) (known as the shrinking core model $^{19}$ ) tends to diverge over $85 \%$ of altered glass $A G(\%)$, because actual glass particles are not spherical.

The apparent diffusion coefficient $D_{B}^{\text {Fick }}$, calculated for $\mathrm{B}$ between 0 and 130 days, is derived from Fick's second law, (b)

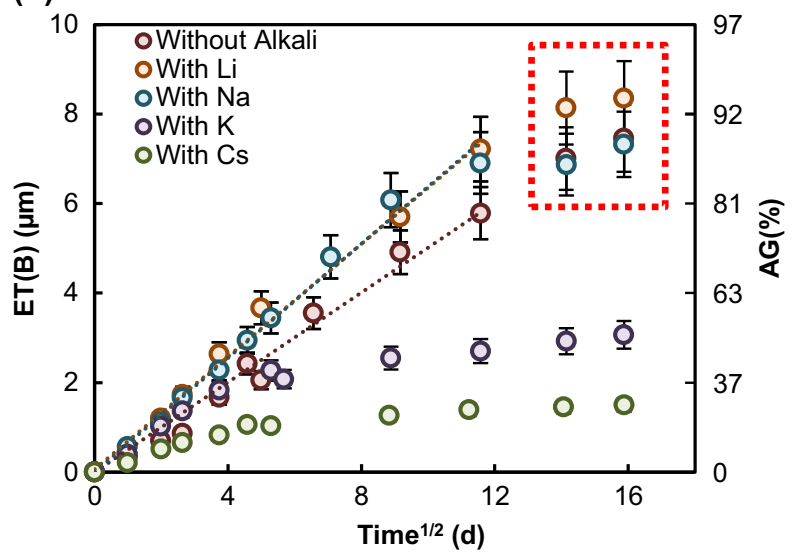

(d)

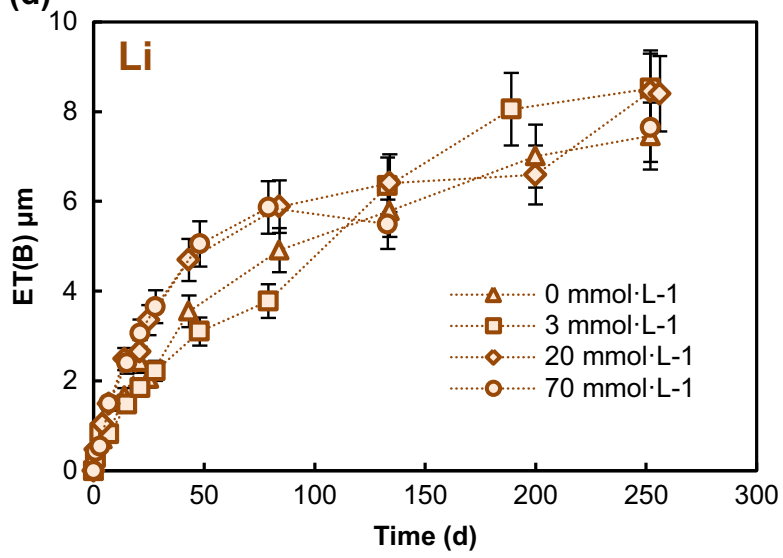

(f)

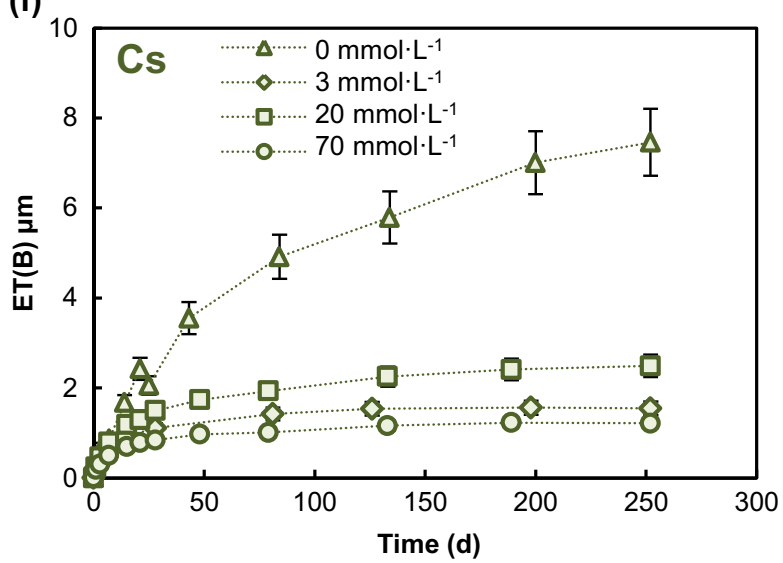

Fig. 1 Data from solution analysis. a Equivalent thickness ET(B) obtained for leaching experiments on 20-40 $\mu \mathrm{m}$ ISG glass powders in Sisaturated conditions with alkali concentration of $20 \mathrm{mmol} \mathrm{L}^{-1}$. ET(B) values obtained on several samples over time are consistent with SEM imaging and ToF-SIMS depth profiling (supplementary material Table S1). b ET(B) versus square root of time. c Ca/B congruence over time. d-f $E T(B)$ over time for various Li concentrations (d), K concentrations (e), and Cs concentrations (f). The error bars represent the standard deviation 
whose resolution in 1D solution is given in Collin, et al. ${ }^{11}$ :

$$
E T(B)=\frac{2}{\sqrt{\pi}} \sqrt{D_{B}^{\text {Fick }} \cdot t}
$$

The diffusion coefficients are similar $\left((3 \pm 0.3)-(4 \pm 0.4) \times 10^{-18} \mathrm{~m}^{2}\right.$ $\mathrm{s}^{-1}$ ) and indicate that the release of mobile species is limited by diffusion through the growing gel layer for these experiments, while another mechanism occurs before $~ 20$ days in the $K$ - and $C s-$ solutions, drastically reducing the release of mobile species.

If $\mathrm{Na}$ and $\mathrm{B}$ releases are congruent for all experiments (refer to supplementary material Fig. S1 a-e for more data), Ca release is highly dependent on the alkali introduced in the solution (Fig. 1c): $\mathrm{Ca}$ dissolves almost congruently with $\mathrm{B}$ and $\mathrm{Na}$ in $\mathrm{K}$ - and $\mathrm{Cs}$ solutions, while it is more retained in gels formed in no alkali-, $L i-$, and $\mathrm{Na}$-solutions.

The ionic strength of the solution also affects the glass alteration kinetics. While with $\mathrm{Li}$ this effect is not notable, $\mathrm{K}$ and Cs have a strong effect: the $\mathrm{K}$ concentration effect is gradual, while the Cs concentration effect, despite being also slightly progressive, is more pronounced (Fig. $1 \mathrm{~d}-\mathrm{f}$ and supplementary material Fig. $\mathrm{S} 1$ f). These differences in alteration kinetics are interestingly correlated to differences in $\mathrm{Ca} / \mathrm{B}$ congruence ratio (Fig. 1c). The more altered glasses powders are those that also display a high retention of $\mathrm{Ca}$ in gels (refer to supplementary material Fig. S1 g-i for more data).

\section{Gel composition}

The gel composition was determined on 3.5-5.5 $\mu \mathrm{m}$ glass powders altered for durations ranging from 1 month to 1 year in Sisaturated conditions, at $90^{\circ} \mathrm{C}, \mathrm{pH}_{90^{\circ} \mathrm{C}} 7$, with alkali concentration of $20 \mathrm{mmol} \mathrm{L}^{-1}$. Note that using smaller particles than in previous experiments does not change the glass dissolution kinetics but makes it possible to obtain fully altered samples. The detailed chemical composition of the gels can be found in Table 1.

The results are consistent with those obtained from the solution analysis: $\mathrm{B}$ and $\mathrm{Na}$ loses are almost complete in each case. A small quantity of $\mathrm{K}$ can be found in each gel due to electrode contamination when measuring the $\mathrm{pH}$. The percentages of remaining $\mathrm{Ca}$ in gel powders are coherent with $\mathrm{Ca}$ quantities found in the solution (Fig. 2a). The retained Ca quantity is higher for glass powders altered in no alkali- and $\mathrm{Li}$-solutions, lesser in $\mathrm{Na}$ solution, and significantly lower in $K$ - and Cs-solutions. This quantity is anticorrelated with that of alkali supplied by the solution and incorporated in the gel (Fig. $2 \mathrm{~b}$ and Table 1), strongly suggesting that $\mathrm{Ca}$ exchanges preferentially with alkali following the order $\mathrm{K}>\mathrm{Cs}>\mathrm{Na}>>\mathrm{Li}$. Interestingly, a rise in the concentration of $\mathrm{K}$ is observed in the sample altered for 1 year compared to that of the sample altered for 1 month, indicating that the material keeps on evolving even after complete $\mathrm{B}$ and $\mathrm{Na}$ loss. Knowing the concentration of alkalis in the bulk solution and the water content in the different gels, the amount of alkali confined in pore water was calculated (supplementary material part 2 and Table S2 c for more information). These quantities are found to represent less than $5 \%$ of the total amount of alkali in the gel structure, indicating that the amount of alkali inside the gel structure is not correlated to the water quantity entering the gel.

The electric charge of the structure was calculated for each gel composition ${ }^{20}$ to assess whether there is an excess of alkali (which would be confirmed by a positive charge). An excess of alkali would lead to a depolymerization of the network with formation of non-bridging oxygen atoms (NBOs). Overall, the charge is found to be balanced within analytical error, proving the absence of excess alkali in each altered structure. Such an observation is highly dependent on $\mathrm{pH}$. Indeed, at higher $\mathrm{pH}$, excess of cationsmainly $\mathrm{Ca}-$ has been observed previously. ${ }^{21}$ Due to the absence of an excess of alkali, the remaining NBOs are expected to be silanol groups. Ca ensures most of the charge compensation in No

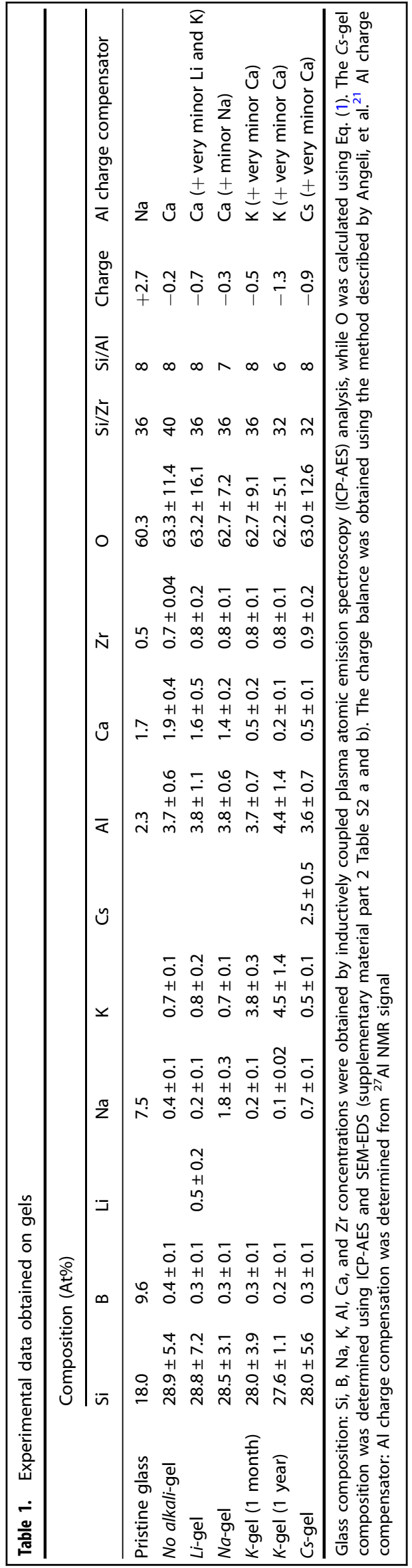




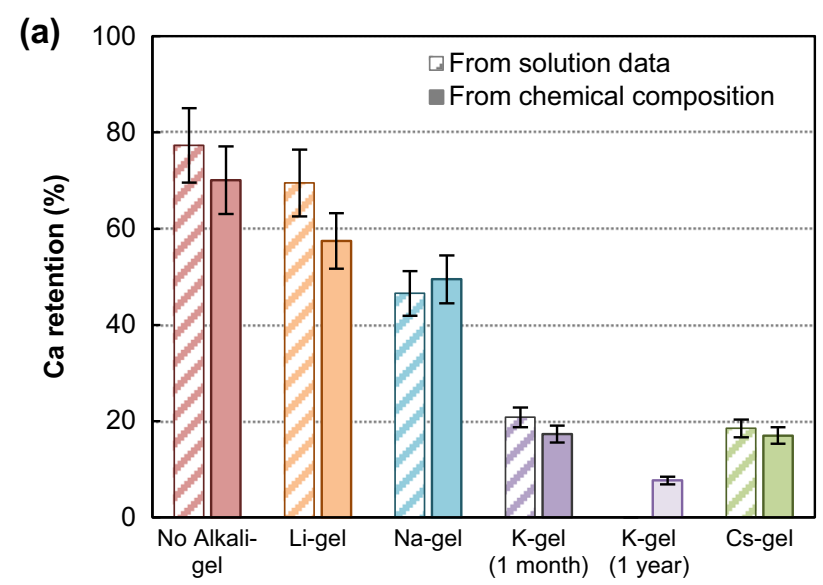

(b)
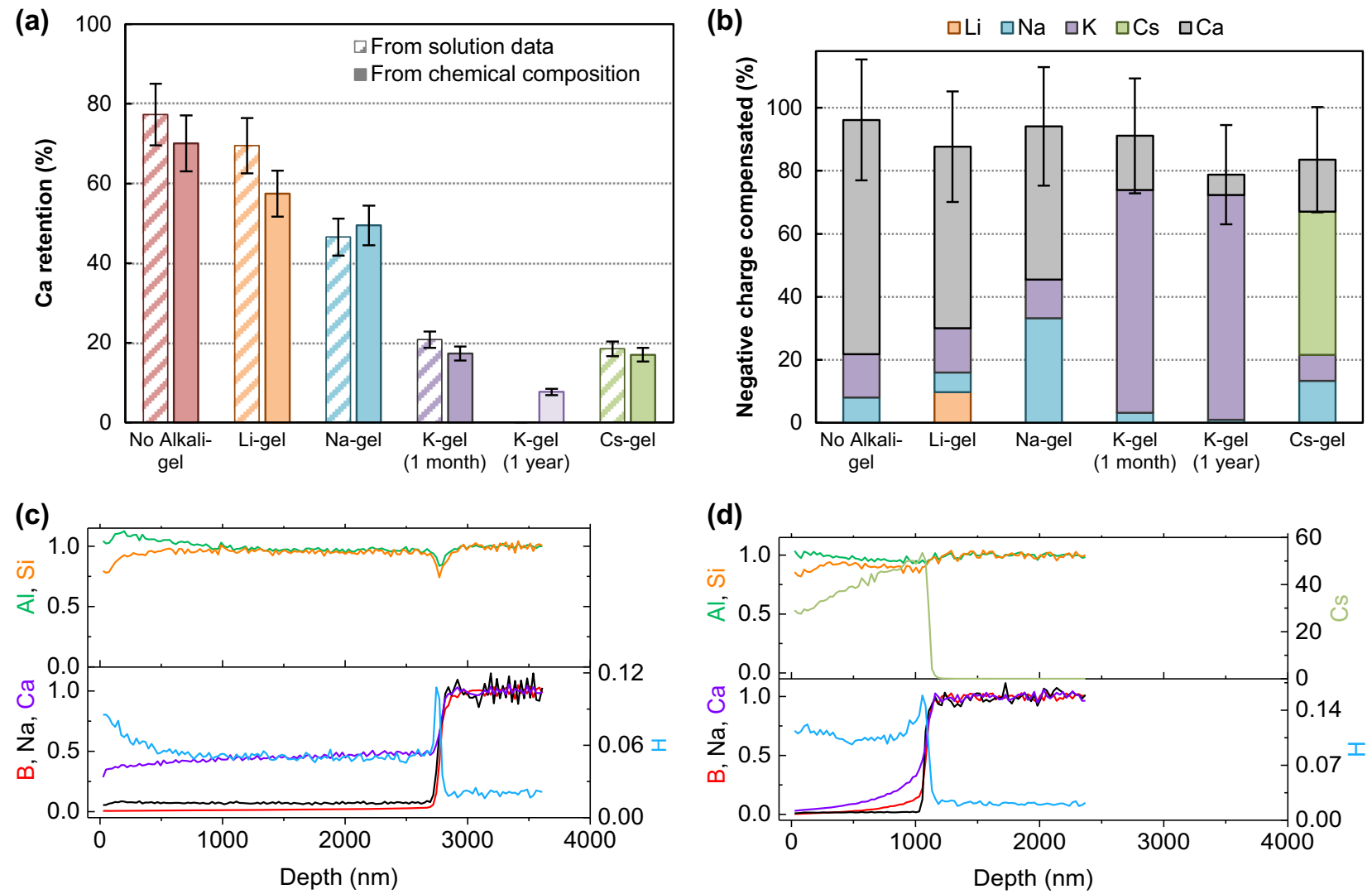

Fig. 2 Chemical analysis data. a Quantity of Ca remaining in each gel structure (\%) obtained from chemical analysis and compared to those calculated from solution data. b Percentage of negative charge compensated by each cation present inside the gel layer (the $\mathrm{K}$ quantities are due to electrode contamination when measuring the $\mathrm{pH}$ ). The error bars represent the standard deviation. c ToF-SIMS data obtained from ISG monolith altered 30 days in a $20 \mathrm{mmol} \mathrm{L}^{-1} \mathrm{Na}$-solution and c 134 days in a $20 \mathrm{mmol} \mathrm{L}^{-1} \mathrm{Cs}$-solution. Si, Al, B, Na, and Ca profiles are normalized to that of $Z r$ to avoid matrix effects; the resulting data are normalized to that measured in pristine glass, providing quantitative information. The $\mathrm{H}$ and $\mathrm{Cs}$ profiles are not normalized. Refer to the Methods section for more information on data normalization

alkali-, $\mathrm{Li}$-, and $\mathrm{Na}$-samples, but is supplanted by $\mathrm{K}$ and $\mathrm{Cs}$ in the $\mathrm{K}$ and Cs-samples, respectively (Fig. 2b).

ToF-SIMS elemental profiles were obtained on two monoliths: one altered 30 days in a $20 \mathrm{mmol} \mathrm{L}^{-1} \mathrm{Na}$-solution and one altered 134 days in a $20 \mathrm{mmol} \mathrm{L}^{-1}$ Cs-solution (Fig. 2c-d). The results are consistent with solution data (supplementary material Fig S1 c and e for more information). For each sample, the drops in concentration observed for every mobile element $(\mathrm{B}, \mathrm{Na}, \mathrm{Ca}$ and $\mathrm{H})$ are located at the same depth $(\sim 2.7 \mu \mathrm{m}$ for the $\mathrm{Na}$-sample and $\sim 1.1 \mu \mathrm{m}$ for the Cs-sample). The widths of these interfacial gradients are found to be similar within measurement error ( $25 \mathrm{~nm}$ for the $\mathrm{Na}$-sample and $\sim 30 \mathrm{~nm}$ for the Cs-sample). The altered layer formed in the $\mathrm{Na}$-solution is homogenous, which is similar to what was observed in a previous study on a sample altered in a no alkali-solution. ${ }^{11}$ The mean retention factor for $\mathrm{Na}$ and $\mathrm{Ca}$ in the $\mathrm{Na}$-sample is of $7 \pm 1 \%$ and $44 \pm 4 \%$, respectively. $\mathrm{Na}$ retention is slightly underestimated compared to the solid analysis data which provides a retention of $\sim 15 \%$, while Ca retention is coherent with the data presented in Fig. 2a. For the Cs-sample, the $B$ and $C a$ retention in the gel is dependent on the depth, with values of $\sim 1-11 \%$ in the first $0.5 \mu \mathrm{m}$ and $\sim 3-30 \%$ from 0.5 to 1.1 $\mu \mathrm{m}$. Such a phenomenon was observed by Gin, et al. ${ }^{10}$ on a sample altered in a solution highly concentrated in $\mathrm{K}(>80 \mathrm{mmol}$ $\mathrm{L}^{-1}$ ). In this medium, the authors also reported that the $\mathrm{B}$ retention in the inner region of the gel increases with time.

Structural analysis of the pristine glass and gels

All 3.5-5.5 $\mu \mathrm{m}$ gel powders were examined using ${ }^{1} \mathrm{H},{ }^{29} \mathrm{Si}^{27} \mathrm{Al}$, and ${ }^{11} \mathrm{~B}$ solid-state NMR spectroscopy. No ${ }^{11} \mathrm{~B}$ signal was detected, confirming that it was almost totally leached out. ${ }^{29}$ Si magic-angle spinning (MAS) Carr-Purcell-Meiboom-Gill (CPMG) NMR spectra and ${ }^{1} \mathrm{H}-{ }^{29} \mathrm{Si}$ cross-polarization MAS (CP-MAS) NMR signal spectra, displayed in Fig. 3a, are similar within experimental noise. A hypothesis for such a similarity is that the presence and nature of the alkali in the solution do not affect the internal network reorganization taking place under Si-saturated conditions. ${ }^{11}$ However, Ca tends to cause a shift of $\delta_{\mathrm{Si}}$ to a more negative chemical shift. ${ }^{22}$ The effect of Ca concentration variation from one gel to another may counterbalance any variations in polymerization. We then cannot rule out the hypothesis that some gels are more polymerized than others.

The two samples altered for 1 month and for 1 year respectively in a $K$-solution were also analyzed to assess whether the structure continues to reorganize after the first month of alteration. Both CPMG and CP-MAS signals are identical (Fig. 3b). As their chemical compositions are relatively similar (Table 1), it can be deduced that while network reorganization still occurs, the degree of order and polymerization of the gel structure is not significantly modified over time.

${ }^{27} \mathrm{AI}$ MAS NMR spectra acquired before and after heat treatment $\left(300^{\circ} \mathrm{C}\right)$ are depicted in Fig. 3c,d. As observed in previous studies, ${ }^{11,23}{ }^{27}$ Al MAS NMR peaks in gels are sharper before heat treatment, which is typical of a hydrated local environment of $\left[\mathrm{AlO}_{4}\right]^{-}$units that dehydrates at high temperature. After heat treatment at $300^{\circ} \mathrm{C}$, the signals are devoid of most surrounding protons leading to a less symmetric environment. As a consequence, the local electric field gradient increases, yielding a broader spectrum. Variations in the spectra widths (Fig. 3d) are 
(a)

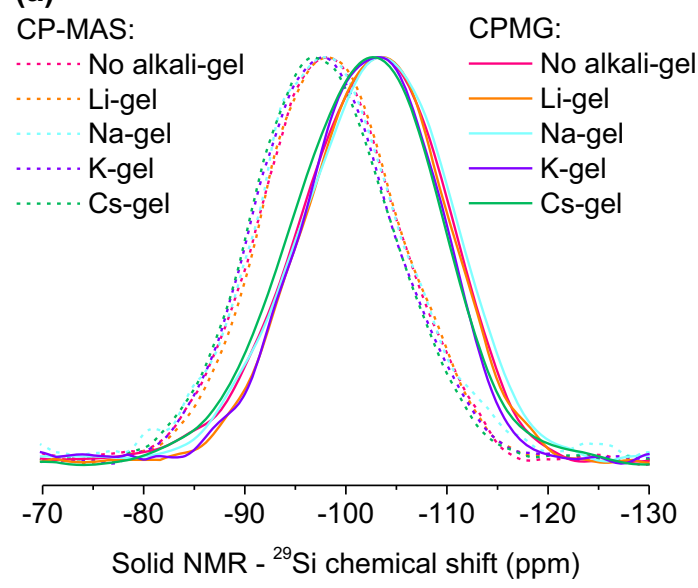

(c)

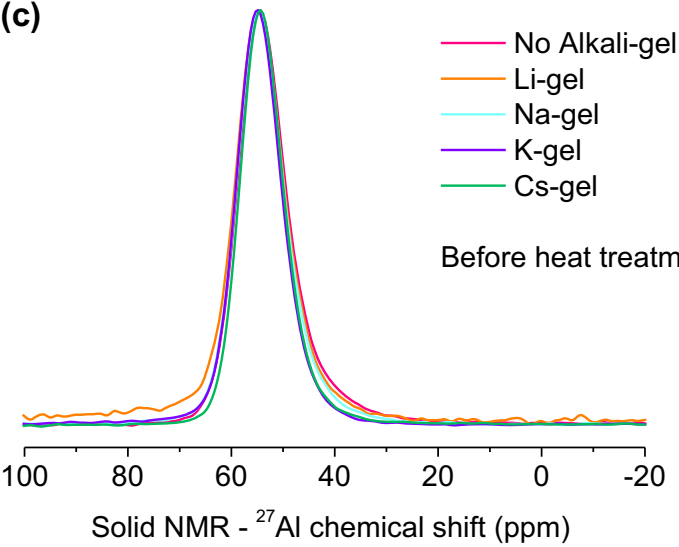

(b)
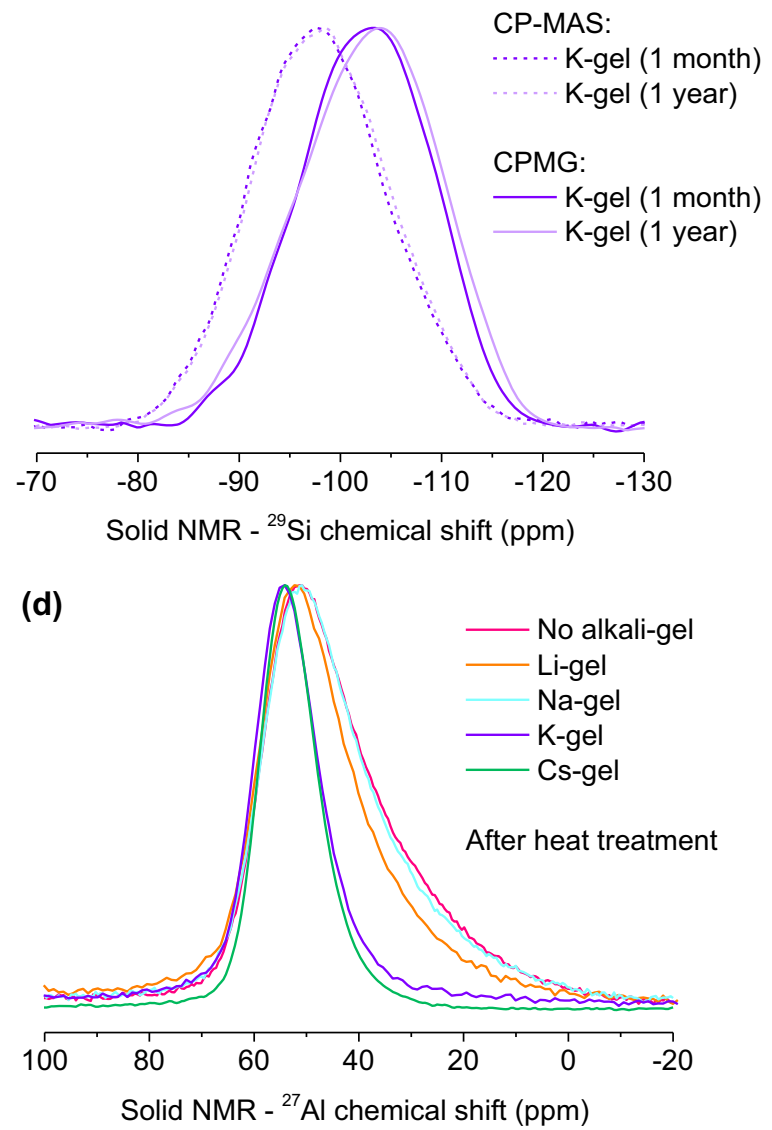

Fig. 3 Solid-state NMR spectroscopy data. a ${ }^{29}$ Si MAS CPMG and CP-MAS NMR spectra of each 3.5-5.5 $\mu \mathrm{m}$ gel powders. b CP-MAS and CPMG NMR spectra of the 3.5-5.5 $\mu \mathrm{m}$ gel powders altered 1 month and 1 year in a K-solution. $\mathbf{c}, \mathbf{d}^{27} \mathrm{Al}$ MAS NMR spectra of each 3.5-5.5 $\mu \mathrm{m}$ gel powders before heat treatment $(\mathbf{c})$ and after heat treatment $\left(300^{\circ} \mathrm{C}\right)(\mathbf{d})$. All spectra are normalized to the same maximum height to facilitate their comparison

indicative of a variation in the $\left[\mathrm{AlO}_{4}\right]^{-}$units charge compensator. $^{24,25}$ For a glass altered in a no alkali-solution, it was demonstrated that the charge compensation is mostly ensured by $\mathrm{Ca}$ remaining in the structure. ${ }^{11} \mathrm{Li}$ - and $\mathrm{Na}$-gels have a signal that is similar to that of the no alkali-gel. By contrast, the signals obtained on $\mathrm{K}$ - and $\mathrm{Cs}$-gels are narrower. To help identify the Al charge compensator, several pristine ISG-based glasses with $\mathrm{Li}, \mathrm{K}$, and Cs replacing Na were prepared, and ${ }^{27} \mathrm{Al}$ MAS NMR signals were acquired for each of these glasses and compared to the gel signals (supplementary material part 3 for more information). The signal of the $L i-g e l$ is similar to that of pristine ISG-Li glass (supplementary material Fig. S3 b). However, the quantity of $\mathrm{Li}$ incorporated in the gel structure is very low and inferior to that of $\mathrm{K}$ (from the $\mathrm{pH}$ electrode contamination). Considering that point, and noticing that the ${ }^{27} \mathrm{Al}$ MAS NMR spectrum is similar to that of the no alkali-gel, it is possible to deduce that $\left[\mathrm{AlO}_{4}\right]^{-}$units are preferentially compensated by $\mathrm{Ca}$. The minor quantity of $\mathrm{Li}$ and $\mathrm{K}$ mostly charge compensate $\left[\mathrm{ZrO}_{6}\right]^{2-}$ units as $\mathrm{Ca}$ quantity inside the gel is not enough to charge compensate every remaining negatively charged units. The signal of the $\mathrm{Na}$-gel differs from that obtained on pristine ISG glass (supplementary material Fig. S3 c); $\left[\mathrm{AlO}_{4}\right]^{-}$units are thus preferentially compensated by $\mathrm{Ca}$, while $\mathrm{Na}$ is supposedly mostly charge compensating $\left[\mathrm{ZrO}_{6}\right]^{2-}$ units rather than $\left[\mathrm{AlO}_{4}\right]^{-}$units. The signals of the $K$ - and $\mathrm{Cs}$-gels are similar to those of their respective ISG-K and ISG-Cs glass counterparts (supplementary material Fig. S3 d and e). This is coherent with the small quantity of $\mathrm{Ca}$ remaining in these gel structures as well as the high quantity of the corresponding alkali incorporated inside the altered structure and taking the role of $\left[\mathrm{AlO}_{4}\right]^{-}$units charge compensator. $\left[\mathrm{AlO}_{4}\right]^{-}$units charge compensators are summarized in Table 1.

Free volume calculation

The volume-constant transformation of glass into gel in $\mathrm{Si}$ saturated conditions was first demonstrated, for each alkali experiment, using white-light vertical scanning interferometry (VSI) and density calculation (supplementary material part 4 for more information). The results obtained for each gel were similar to those obtained by Collin, et al. ${ }^{11}$ The free volumes generated by the dissolution of mobile $\mathrm{B}, \mathrm{Na}$, and $\mathrm{Ca}$, and $\mathrm{Ca}$ alkali exchange were then calculated considering pristine glass and gel compositions, following the method described by Collin, et al. ${ }^{11}$ Although the uncertainties of this method are significant, a trend seems to emerge: slightly higher free volume values are found for no alkaliand $\mathrm{Li}$-gels, while the value decreases gradually for $\mathrm{Na}-\mathrm{K}$-, and $\mathrm{Cs}$ gels (Table 2). This is consistent with the fact that $\mathrm{Ca}$ tends to be exchanged with cations with larger ionic radius $(\mathrm{Na}, \mathrm{K}$ and $\mathrm{Cs}$ ).

Water speciation analysis

${ }^{1} \mathrm{H}$ NMR signals were acquired for every $3.5-5.5 \mu \mathrm{m}$ gel powders. Spectra are normalized to the same sample weight so that their areas are reflective of the proton content. The no alkali-, $L i-$, and $\mathrm{Na}$-gels appear to be more hydrated than the $K$ - and Cs-gels (Fig. 4a). The $K$-gels altered for 1 month and for 1 year show a little difference, although the sample altered for 1 year is slightly less 
hydrated (Fig. 4b). All the signals display similar shapes (refer to supplementary material Fig. S5 a), suggesting a similar proton speciation population in all samples.

TGA was used to quantify the total water content inside gels. This analytical technique was applied to the $3.5-5.5 \mu \mathrm{m}$ gel powders; the resulting data are displayed in Fig. 4c. These data are strongly correlated with those obtained by ${ }^{1} \mathrm{H}$ MAS NMR (Fig. 4d), despite uncertainties at low water content leading to a calibration curve that does not run through the origin (possibly due to sample rehydration, see supplementary material Fig. $\mathrm{S} 5 \mathrm{~b}$ ). Such a curve will therefore only be used for a sample (K-gel altered 1 year) that is situated in the central zone of the graph, where the correlation is the best.

Using the method detailed by Collin, et al., ${ }^{11}$ the population of water species was determined for every gel from ${ }^{1} \mathrm{H}$ MAS NMR spectra. Each proton species has a distinct contribution to the ${ }^{1} \mathrm{H}$ NMR signal. The positions of these contributions were found to be globally identical in each gel from Hahn Echo (HE) experiments (supplementary material Fig. S5 c to m). Molecular water $\left(\mathrm{H}_{2} \mathrm{O}_{\mathrm{mol}}\right)$ contribution is centered at $\sim 4.7 \mathrm{ppm}$, while hydroxyl groups forming $\mathrm{H}$ bonds $\left(-X-\mathrm{OH}_{\mathrm{HB}}\right)$ contribution is centered at $\sim 7.1 \mathrm{ppm}$. Hydroxyl species that do not form $\mathrm{H}$ bonds ("free" $-X-\mathrm{OH}$ ) contribution is centered at $1.8 \mathrm{ppm}$. A deconvolution of the ${ }^{1} \mathrm{H}$ NMR signal for each altered sample was performed considering these contributions (supplementary material Fig. S5 $d$ to $n$ ), providing the $\mathrm{H}$ atoms repartitions as presented in Table 2. As presumed from the shape of the ${ }^{1} \mathrm{H}$ NMR signals, a similar $\mathrm{H}$ repartition is found for every gel.

Combining the $\mathrm{H}$ repartition with TGA data and chemical analysis, the volumes occupied by the water species $\left(\mathrm{H}_{2} \mathrm{O}_{\text {mol }}\right.$ only and $\mathrm{H}_{2} \mathrm{O}_{\mathrm{mol}}+$ "free" $-\mathrm{X}-\mathrm{OH}+-\mathrm{X}-\mathrm{OH}_{\mathrm{HB}}$ ) can be calculated (Table $2)$, as well as the $O$ repartition. ${ }^{11}$ Oxygens are found inside the altered sample as bridging-oxygen $\mathrm{O}_{\text {во }}$ and non-bridging-oxygen (hydroxyl species) $\mathrm{O}_{\mathrm{NBO}}$, as well as water-oxygen $\mathrm{O}_{\mathrm{H} 2 \mathrm{O}}$. $\mathrm{O}$ repartition is dependent on total water quantity: the less hydrated samples therefore display a higher percentage of $\mathrm{O}_{\mathrm{BO}}$ (Table 2) and are more polymerized.

\section{DISCUSSION}

The effect of alkalis on ISG glass alteration under silica-saturated and neutral $\mathrm{pH}$ conditions was assessed in this study. The glass alteration rates, calculated between 25 and 80 days, $r_{45-80}$, are similar for glass powders altered in no alkali-solution, Li-solution and $\mathrm{Na}$-solution. They are however divided by 6 when $\mathrm{K}$ or $\mathrm{Cs}$ are introduced in the solution (supplementary material Table S6 a for more data). The absence of $\mathrm{Li}$ effect on glass alteration is confirmed by experiments using a large range of Li concentrations. By contrast, $\mathrm{K}$ influences the glass alteration gradually from low to high solution ionic strength, while Cs displays a striking effect regardless of its concentration in the solution $\left(r_{45-80}\right.$ is reduced by a factor of 5.5 between 0 and $3 \mathrm{mmol} \mathrm{L}^{-1}$ of $\mathrm{Cs}$, and only a factor of 2 between 3 and $70 \mathrm{mmol} \mathrm{L}^{-1}$ of $\mathrm{Cs}$ in solutions).

Both solution and solid analyses confirm that $\mathrm{B}$ and $\mathrm{Na}$ releases during glass alteration in all tested solutions are almost complete. However, the retention of $\mathrm{Ca}$ in the gel is highly dependent on the nature of the alkali added to the solution. A higher selectivity of the gel is observed for $\mathrm{Na}, \mathrm{K}$, and $\mathrm{Cs}$ rather than Li following the order

$\mathrm{K}>\mathrm{Cs}>\mathrm{Na} \gg \mathrm{Li}$

Such an order is surprising at first, considering that previous works have shown a higher mobility of Li than the other cations, with an unexpected ability of Li to diffuse inside the pristine glass in aqueous ${ }^{9}$ and non-aqueous media. ${ }^{26,27}$ However, while the capacity of aqueous Li to diffuse in glass was observed, it was not quantified. The order observed here is close to the order of the Hofmeister series (also called lyotropic series). ${ }^{28}$ This series, used 


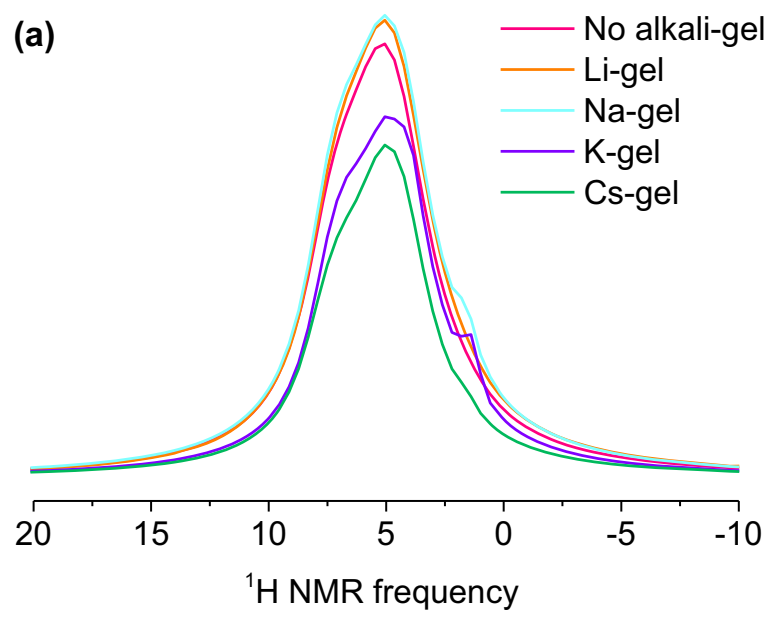

(c)

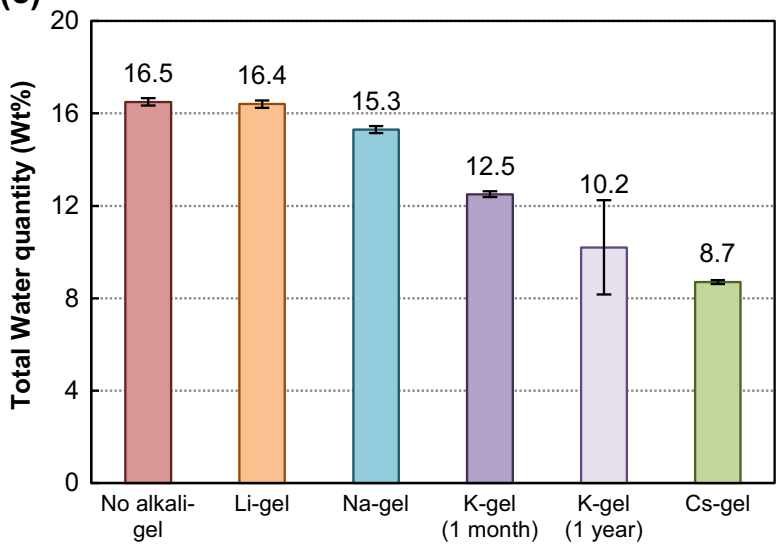

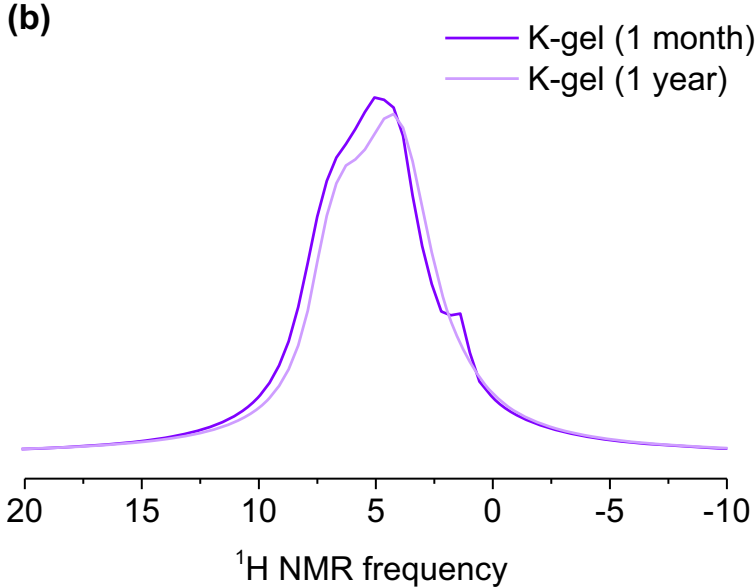

(d)

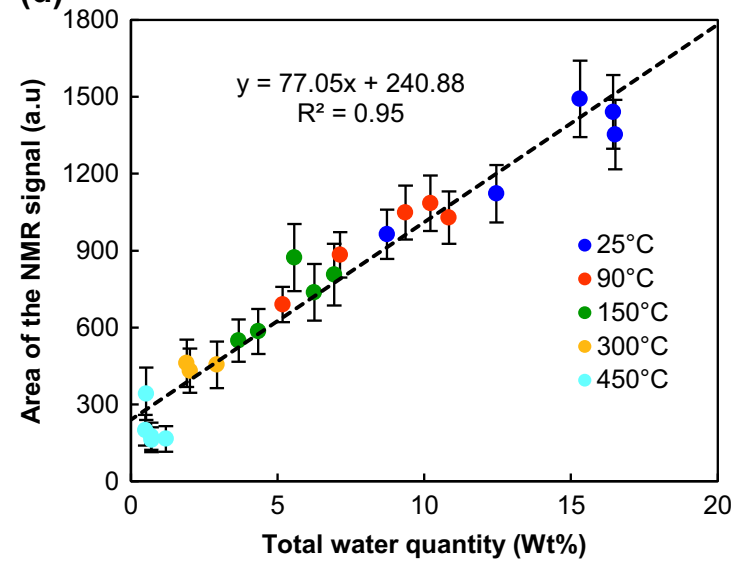

Fig. $4{ }^{1} \mathrm{H}$ MAS NMR spectroscopy and TGA performed on each gel. a ${ }^{1} \mathrm{H}$ MAS NMR spectra of each gel. Spectra are normalized to the sample mass. $\mathbf{b}$ Comparison of ${ }^{1} \mathrm{H}$ MAS NMR spectra of the $K$-gels altered for 1 month and for 1 year. $\mathbf{c}$ Total water quantification obtained from TGA (data for $K$-gel (1 year) is calculated from the calibration curve given in d). $\mathbf{d}$ Calibration curve obtained combining ${ }^{1} \mathrm{H}$ MAS NMR and TGA data for each sample (the uncertainty bars are smaller than the symbols for water quantity obtained by TGA). The error bars represent the standard deviation

first as a classification of the ability of ions to increase or decrease proteins solubility, has also been observed in clay selectivity for cations. ${ }^{29} \mathrm{Cs}$ and $\mathrm{K}$ are reversed in the lyotropic series, compared to what is observed here. However, several uncertainties (mainly analysis error and $\mathrm{K}$ contamination in the Cs-solution leading to a Cs-K competition inside the gel structure) exist such that we cannot exclude the $\mathrm{K} \approx \mathrm{Cs}>\mathrm{Na}>>\mathrm{Li}$ order.

Alkalis act as charge compensators for clays, similar to what they do inside the gel structure, justifying a comparison between both materials to propose a hypothesis explaining the same observed selectivities. Many studies conducted on clay selectivity proposed a hypothesis to explain why certain ions were more retained than others. The hydrated radius is often cited as a reason for selectivity on a clay surface ${ }^{29}$ and on amorphous negatively charged silica surfaces. ${ }^{30}$ However, this hypothesis is often rebutted when considering cations entering inside a clay structure, as it is in contradiction with many observed selectivities for various clay materials. ${ }^{29}$ Another model, based on the Eisenman model for ion-specific glass electrodes, ${ }^{31}$ explains cation selectivity by a competition between two electrostatic forces: the force of attraction between the cation and its hydration shell, and the force of attraction between the cation and the material. ${ }^{29,32}$ According to this model, ions that are weakly hydrated such as $\mathrm{K}$ and Cs (see Table 3) have an attraction force to their hydration shell that is more likely to be lower than the attraction force
Table 3. Alkali properties

\begin{tabular}{lllll}
\hline Cation & $\begin{array}{l}R^{15,42} \\
(\AA)\end{array}$ & $\begin{array}{l}R_{\text {hyd }}{ }^{15} \\
(\AA)\end{array}$ & $N_{\mathrm{H}_{2} \mathrm{O}}{ }^{15}$ & $\begin{array}{l}\Delta \mathrm{H}_{\mathrm{H}_{2} \mathrm{O}}{ }^{35} \\
\left(\mathrm{~kJ} \mathrm{~mol}^{-1}\right)\end{array}$ \\
\hline $\mathrm{Li}$ & 0.94 & 3.82 & 4 & -515 \\
$\mathrm{Na}$ & 1.17 & 3.58 & 5 & -404 \\
$\mathrm{~K}$ & 1.49 & 3.31 & 6 & -322 \\
$\mathrm{Cs}$ & 1.86 & 3.29 & 8 & -263 \\
$\mathrm{Ca}$ & 1.00 & 4.12 & 8 & n.a. \\
\hline
\end{tabular}

$R$ ionic radius. $R_{\text {hyd }}$ hydrated ionic radius. $\mathrm{N}_{\mathrm{H}_{2} \mathrm{O}}$ number of water molecules in the first hydration shell of the cation. $\Delta H_{\mathrm{H}_{2} \mathrm{O}}$ hydration energy in solution ${ }^{43}$ n.a. not applicable

between the cation and the material. This model is coherent with the Hofmeister series, and is also a likely hypothesis for our gel structure selectivity for cations. The more strongly hydrated cation (Li) is nearly not exchanged with $\mathrm{Ca}$, while $\mathrm{Na}$ (a mildly hydrated cation) exchanges more. $\mathrm{K}$ and $\mathrm{Cs}$, the less energetically hydrated cations, are almost totally exchanged.

Al changing of charge compensator from one gel to another (Table 1) can be seen as a consequence of the gel structure selectivity for some cations. When Ca is still present inside a gel, it 
preferentially charge-compensates $\left[\mathrm{AlO}_{4}\right]^{-}$units as demonstrated by the Na-experiment ${ }^{27} \mathrm{Al}$ MAS NMR signal: despite the presence of $\mathrm{Na}$ inside the altered structure, $\left[\mathrm{AlO}_{4}\right]^{-}$units are mostly chargecompensated by $\mathrm{Ca}$. By contrast, for low Ca retention, cations from the solution supplant $\mathrm{Ca}$ as $\left[\mathrm{AlO}_{4}\right]^{-}$units charge compensator.

Beyond the local effect of alkalis supplied by the solution on the charge compensation of negatively charged units within the gel, the gel structure selectivity with respect to alkali also appears to have consequences on water quantity found inside the gel. In order to explain this trend, the free volume that is supposed to be found inside the gel after mobile species leaching and $\mathrm{Ca}$ /alkali exchange are compared to the volume occupied by water species $\left(\mathrm{H}_{2} \mathrm{O}_{\text {mol }}+\right.$ "free" $\left.-\mathrm{X}-\mathrm{OH}+-\mathrm{X}-\mathrm{OH}_{\mathrm{HB}}\right)$. Indeed, as $\mathrm{Ca}$ is replaced by $\mathrm{Na}$, K, or $\mathrm{Cs}$, cations whose ionic radii are larger than that of $\mathrm{Ca}$ (Table 3), smaller free volumes are expected, which would be consistent with the decrease in water quantity observed above. However, the volume occupied by all water species $\left(\mathrm{H}_{2} \mathrm{O}_{\text {mol }}\right.$ + "free" $-\mathrm{X}-\mathrm{OH}+-\mathrm{X}-\mathrm{OH}_{\mathrm{HB}}$ ) is greater than the free volume (Fig. $5 a$ ). This is coherent with the fact that hydroxyl species ("free" $\mathrm{X}-\mathrm{OH}+-\mathrm{X}-\mathrm{OH}_{\mathrm{HB}}$ ) can be considered as part of the network and not of the porosity. Yet, no clear correlation is observed between the free volume and the volume occupied by water molecules alone $\left(\mathrm{H}_{2} \mathrm{O}_{\mathrm{mol}}\right)$ (Fig. 5a). This would indicate that the calculation of the free volume from steric considerations is too simple and should consider the network re-organization following the release of $B$ as it was shown in Collin, et al. ${ }^{11}$ However, we can see that the best correlations are obtained for the $\mathrm{Li}$ - and No alkali-sample, i.e. samples with low Ca/alkali exchange. Cations such as $\mathrm{K}$ and $\mathrm{Cs}$ could therefore have an unforeseen effect on the water quantity entering the gel layer. Our data do not allow us to conclude on this hypothesis, but molecular dynamic simulation of alkali effect on water quantity inside nanoporosity could give more information.

The water quantities found inside the gel are well correlated to the degree of glass alteration measured from boron release (Fig. $5 b)$. This observation is also supported by ToF-SIMS profiles: those obtained for Cs-sample (Fig. 2d) and in K-sample (previously published by Gin, et al. ${ }^{10}$ ) display a retention of $\mathrm{B}$ in the inner part of the gel, which is characteristic of a strong passivation effect, ${ }^{10}$ while no retention is observed for the $\mathrm{Na}$-sample (Fig. $2 \mathrm{C}$ ) and $\mathrm{No}$ alkali-sample (previously published by Collin, et al. ${ }^{11}$ ).

Another global effect is observed due to this decrease of water quantity: the percentage of NBOs-a good proxy of gel reorganization-is significantly diminished in $K$ - and Cs-gels relative to the other gels (Table 2 ). In general, a high degree of reorganization favors pore closure leading to a lower glass dissolution rate. ${ }^{33-35}$ To evaluate this effect of reorganization on gels properties, we have measured their dissolution rate $\left(r_{0}\right)$. Tests were conducted in dilute conditions, i.e., far from equilibrium, to avoid any effect of dissolved gel species on the Gibbs free energy of reaction (supplementary material Table $\mathrm{S} 6 \mathrm{~d}$ ). Despite the fact that $r_{0}$ does not appear to be very sensitive to variation of the gels composition and structure, and that the uncertainty is approximately $25 \%,{ }^{36}$ a lower $r_{0}$ is measured for the Cs-rich gel than for the other gels. This indicates that Cs improves both the passivation properties and the resistance of the gel towards hydrolysis.

The gel has a dynamic structure, and reorganization dramatically affects its passivation properties. ${ }^{11,35}$ This raises the question on the effect of aging of the gel structure. This question was studied here by comparing a sample altered in a $K$-solution for 1 month to one altered in similar conditions for 1 year. A slight enrichment of $\mathrm{K}$ is observed, indicating that the $\mathrm{Ca}-\mathrm{K}$ exchange process is slightly slower than $\mathrm{B}$ and $\mathrm{Na}$ release, as it continues after the release of the other mobile species. Overall, the two gels are similar, with identical degree of polymerization. The potential evolution of the material formed during the first month of alteration appears to be slow enough to be undetectable. The main mechanisms leading to the differences in the alteration kinetics appear to happen during the first month depending on the alkali in the solution, meaning that the evolution over time of each gel might differ. It is thus difficult to extend the conclusion stated above to the other alkali-samples. This could be further investigated in future studies.

To conclude, this study demonstrated the ability of certain alkalis to decrease glass alteration kinetics when present in solutions. It is demonstrated that $\mathrm{K}$ and $\mathrm{Cs}$ can exchange with $\mathrm{Ca}$ and compensate negatively charged $\mathrm{Al}$ units in a gel. As a consequence, $K$ - and Cs-gels are less hydrated than the others, and thus more passivating. One must however keep in mind that Ca mobility is highly pH-dependent. ${ }^{21}$ Such exchange might be different at more alkaline $\mathrm{pH}$.

It is also found that the Cs-rich gel is more resistant to hydrolysis than the others. These findings could be used in the future to improve glass formulation to come up with intrinsically more durable materials. However, replacing small alkali by bigger one often results in a higher viscosity of the molten glass, which is an issue for processing nuclear glass. Another idea could be the design of engineered barriers containing alkali salts (such as $\mathrm{CsCl}$ ) surrounding glass canisters in future geological disposal facilities to optimize geochemical conditions. (a)

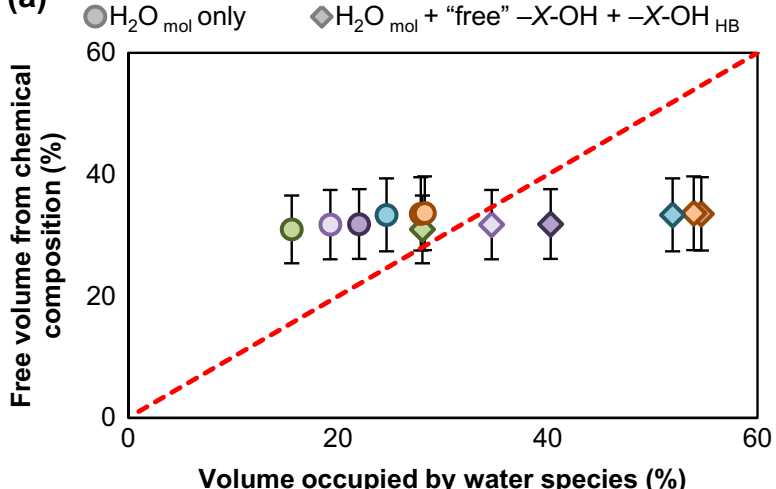

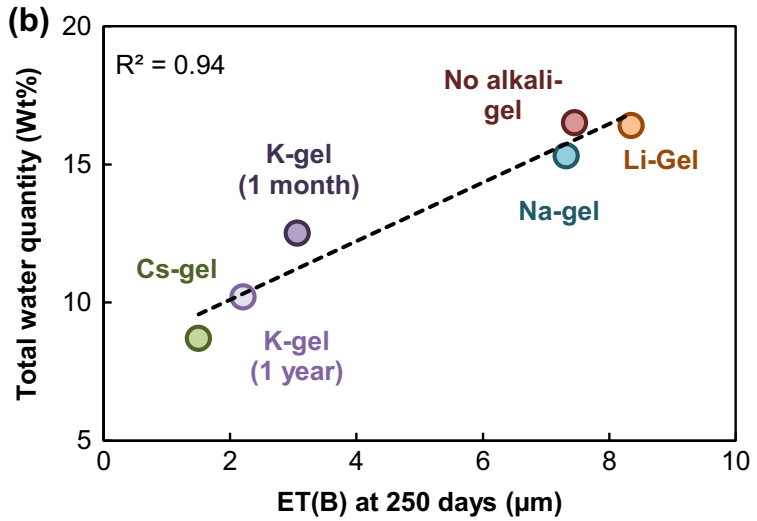

Fig. 5 Data comparison. a Volume occupied by water species versus free volume from mobile species release (the error bars are smaller than the symbols for the volume occupied by water species). The red dashed line is the line $x=y$. b Total water quantity (from TGA) versus the B equivalent thicknesses at 250 days for each sample (the error bars are smaller than the symbols). The black dashed line is the linear regression between data. The error bars represent the standard deviation 


\section{METHODS}

Leaching experiments

All experiments were performed on an ISG batch prepared by MoSci Corporation (Rolla, MO, USA). ${ }^{10}$ The glass was crushed into powder, which was sieved before washing in acetone and pure ethanol to remove fine particles. Leaching experiments were conducted on the fraction with particles of $20-40 \mu \mathrm{m}$ in size for the alteration kinetic study, and on the 3.5-5.5 $\mu \mathrm{m}$ size fraction to obtain a totally altered glass powder for solid characterization and initial rate measurements. Refer to Collin, et al. ${ }^{11}$ for more information on powder preparation.

All experiments were conducted in perfluoroalkoxy reactors using $18.2 \mathrm{M} \Omega \mathrm{cm}$ deionized water initially saturated with respect to amorphous silica $\left(C_{0}(\mathrm{Si})=143 \pm 12 \mathrm{mg} \mathrm{L}^{-1}\right.$ at $\left.\mathrm{pH} 90^{\circ} \mathrm{C} 7\right)$. $\mathrm{SiO}_{2}$ was introduced under agitation at $90^{\circ} \mathrm{C}$ until total dissolution occurred. Various alkali chloride salts $(\mathrm{LiCl}, \mathrm{NaCl}, \mathrm{KCl}$, and $\mathrm{CsCl}$ ) were then added to the solution with different concentration values.

The $\mathrm{pH}$ was maintained at $7.0 \pm 0.5$ during the experiment by adding small quantities of a $0.5 \mathrm{~N}$ ultrapure nitric acid solution. The solution was regularly sampled over time. The samples were filtered ( $0.45 \mu \mathrm{m}$ cutoff) and analyzed by spectrophotometry (Cary ${ }^{\circledast} 50$ Scan UV-Vis spectrophotometer for B and Si concentrations, with methods similar to DIN 38405-17 and ASTM D959-10, respectively) and inductively coupled plasma atomic emission spectroscopy (ICP-AES; Thermo Scientific iCAP ${ }^{\mathrm{TM}} 6000$ Series).

Alteration kinetic study. Specimens of $200 \mathrm{mg}$ of the $20-40 \mu \mathrm{m}$ glass powder and two monoliths measuring $0.5 \times 0.5 \times 0.2 \mathrm{~cm}$, polished to $1 \mu \mathrm{m}$ on the two largest sides, were introduced in $0.5 \mathrm{~L}$ of silica-saturated solution at $90^{\circ} \mathrm{C}\left(\mathrm{S} / \mathrm{N}=34 \mathrm{~m}^{-1}\right.$ with $S_{\text {geo }}$ powder $\left.=0.08 \mathrm{~m}^{2} \mathrm{~g}^{-1}\right)$. Alkali salts were then introduced in the solution with the following concentrations:

- 3, 20, and $70 \mathrm{mmol} \mathrm{L}^{-1}$ for $\mathrm{LiCl}, \mathrm{KCl}$, and $\mathrm{CsCl}$,

- $20 \mathrm{mmol} \mathrm{L}^{-1}$ for $\mathrm{NaCl}$

- a reference without alkali (except $\mathrm{K}$ due to electrode contamination $<1 \mathrm{mmol} \mathrm{L}^{-1}$ ).

Note that the $20 \mathrm{mmol} \mathrm{L}^{-1} \mathrm{~K}$ experiment was reproduced three times, and the results were found to be consistent (supplementary information Fig. S1 j), validating the repeatability of the procedure. The first monoliths were withdrawn after 25 days and the second after 134 days. Various parameters were derived from the solution analysis data, such as the altered glass percentage and equivalent thickness (refer to Collin, et al. ${ }^{11}$ for more information).

Preparation of fully altered glass samples. Samples of $\sim 500 \mathrm{mg}$ of $3.5-5.5$ um glass powder were introduced in $1 \mathrm{~L}$ of silica-saturated solution at $90^{\circ}$ $C\left(S / V=274 \mathrm{~m}^{-1}\right.$ with $\left.S_{\text {geo }}=0.55 \mathrm{~m}^{2} \mathrm{~g}^{-1}\right)$ with alkali concentration of $20 \mathrm{mmol} \mathrm{L}^{-1}$. The solution was regularly checked over time until total $\mathrm{B}$ release from the glass had occurred in each case (approximatively 1 month of alteration). Note that an additional experiment was performed with a solution containing $\mathrm{K}$ until 1-year duration. The solutions were then filtered using a Büchner funnel, and the resulting altered glass powders called gel powders were dried for $24 \mathrm{~h}$ at $50^{\circ} \mathrm{C}$ and stored in a desiccator.

Initial dissolution rate measurement. The initial dissolution rates of both pristine glass and gels were measured by static alteration measurements at $\mathrm{pH}_{90}{ }^{\circ} \mathrm{C} 7$ in deionized water. In contrast to the previous experiments, no silica was added in the onset solution. Duplicates were prepared on 3.5-5.5 $\mu \mathrm{m}$ pristine glass and gel powders $\left(S / V=0.18 \mathrm{~cm}^{-1}\right)$ to ensure repeatability of the experiment. The Si concentration was monitored over time by spectrophotometry and ICP-AES. For more extensive details on the procedure, please refer to Fournier, et al. ${ }^{36}$

\section{Solid analysis}

Solid analyses were performed on the $3.5-5.5 \mu \mathrm{m}$ gel powders and on monoliths altered in a $20 \mathrm{mmol} \mathrm{L}^{-1}$ alkali solution.

Chemical analysis. A small fraction of each altered $3.5-5.5 \mu \mathrm{m}$ glass powder was dissolved in an acid solution $\left(10 \mathrm{HCl}+5 \mathrm{HNO}_{3}+4 \mathrm{HF}\right)$. The resulting solutions were analyzed by ICP-AES (Thermo Scientific iCAP ${ }^{\text {TM }}$ 6000 Series) to quantify Si, B, Al, Ca, Zr, Li, Na, K and Cs. Two analyses were conducted for repeatability. $O$ in the gels was considered using the following equation:

$\mathrm{O}_{\text {altered glass }}=\sum \mathrm{O}_{i \text { pristine glass }} \frac{[i]_{\text {altered glass }}}{[i]_{\text {pristine glass }}}$

where $i=\mathrm{Si}, \mathrm{B}, \mathrm{Na}, \mathrm{Al}, \mathrm{Ca}$, and $\mathrm{Zr}, \mathrm{O}_{i}$ pristine glass being therefore the number of $\mathrm{O}$ atoms associated with each element in the pristine glass.

Density calculation. The densities of both the pristine glass and the gels were assessed using a model developed by Fluege $^{37}$ for calculating the room-temperature glass density using its composition: this model does not consider water within the sample. Another model, developed by lacovino, ${ }^{38}$ which considers water, was also used for the gel density calculation, but this could not be applied to the pristine glass as the model does not consider $B$.

Depth profiling analysis. The monoliths withdrawn from $\mathrm{Na}$ (after 25 days) and Cs (after 134 days) experiments were analyzed using time-of-flight secondary ion mass spectrometry (ToF-SIMS: IONTOF TOF 5). An O ion beam was set at $2 \mathrm{keV}$ and $510 \mathrm{nA}$ and used for surface abrasion $(200 \mathrm{x}$ $200 \mu \mathrm{m})$. Actual analysis was provided by a Bi ion sputtering beam ( $25 \mathrm{keV}$, $2 \mathrm{pA}, 30 \times 30 \mu \mathrm{m})$ followed by ToF investigation of secondary ions extracted from the monolith. The surface was neutralized during analysis by a low-energy electron flux $(<20 \mathrm{eV})$. Measuring the depth of the final crater allowed an elemental profile depth calibration.

$\mathrm{Si}, \mathrm{Al}, \mathrm{B}, \mathrm{Na}$, and $\mathrm{Ca}$ profiles were then normalized to that of $\mathrm{Zr}$ to avoid matrix effects. $\mathrm{Zr}$ was chosen as it was not leached in the solution during the experiment. ${ }^{33}$ The resulting data were normalized to the mean value measured in pristine glass to extract quantitative information (Eq. (3)).

$$
C(i)=\frac{[i / Z r]}{[i / Z r]_{\text {pristine glass }}}
$$

with $i=\mathrm{Si}, \mathrm{Al}, \mathrm{B}, \mathrm{Na}$, and $\mathrm{Ca}$. The $\mathrm{H}$ profile was not normalized, and was thus only used to evaluate the position of the alteration front.

White-light vertical scanning interferometry (VSI). In order to assess the volume change during glass alteration in the Si-saturated solution, the surfaces of glass monoliths were partially coated using room-temperature vulcanization (RTV) silicone. ${ }^{39}$ The RTV silicone held at $\mathrm{pH} 90^{\circ} \mathrm{C} 7$ was checked prior to the experiment. The monolith was then altered for 15 days in conditions similar to those described above. The silicon RTV coating was removed and the sample surface was analyzed by VSI (FOGALE Nanotech, magnification 10). The difference between the mean height values of the coated and uncoated surfaces was measured. The uncertainty was determined from the height variations of both sections. ${ }^{39}$

Thermogravimetric analysis. TGA analyses were performed on a Seratum TG-DSC 92-16.18, under a flow of $\mathrm{Ar}$ in an $\mathrm{Al}_{2} \mathrm{O}_{3}$ crucible. Samples of $3.5-5.5 \mu \mathrm{m}$ pristine glass and gel glass powders were analyzed $(\sim 70 \mathrm{mg}$ for each sample). For the pristine glass, a typical heating ramp of $10^{\circ} \mathrm{C} \mathrm{min}^{-1}$ was used between room temperature and $1200^{\circ} \mathrm{C}$. For the altered samples, an increased rate $\left(30^{\circ} \mathrm{C} \mathrm{min}^{-1}\right)$ was used to attain specific temperatures of $90,150,300$, and $450^{\circ} \mathrm{C}$, with $2 \mathrm{~h}$ plateaus at each temperature. A final heating ramp of $10^{\circ} \mathrm{C} \mathrm{min}^{-1}$ was then performed to reach $1200^{\circ} \mathrm{C}$.

NMR spectroscopy. ${ }^{1} \mathrm{H}$ and ${ }^{29} \mathrm{Si}$ magic-angle spinning (MAS) nuclear magnetic resonance (NMR) analyses were performed on a Bruker Avance WB $300 \mathrm{MHz}$ spectrometer (magnetic field 7.05 T). A Bruker $4 \mathrm{~mm}$ (external diameter of $\mathrm{ZrO}_{2}$ rotor) cross-polarization magic-angle spinning (CP-MAS) probe was used at a sample spinning frequency of $10 \mathrm{kHz}$. The sample mass was $90 \mathrm{mg}$ in average.

${ }^{29} \mathrm{Si} /{ }^{1} \mathrm{H}$ CP-MAS NMR spectra were collected using contact times ranging from $2-8 \mathrm{~ms} .{ }^{29} \mathrm{Si}$ MAS NMR spectra were acquired, using the Carr-Purcell-Meiboom-Gill (CPMG) pulse sequence ${ }^{40}$ with a recycle delay ranging from $2 \mathrm{~s}$ for altered samples, which were found to relax faster owing to protons, and $20 \mathrm{~s}$ for pristine glasses.

${ }^{1} \mathrm{H}$ MAS NMR spectra were obtained by direct acquisition (DA) and using a Hahn Echo (HE) pulse sequence with varying rotor-synchronized echo delays ranging from 100 to $80000 \mu \mathrm{s} .{ }^{1} \mathrm{H}$ NMR spectra were deconvolved using the Dmfit program, ${ }^{41}$ considering a mixed Gaussian/Lorentzian model. Positions of each contribution were determined using the HE data and the width and amplitude were left free.

${ }^{11} \mathrm{~B}$ and ${ }^{27} \mathrm{Al}$ MAS NMR spectra were collected on a Bruker Avance II 500WB spectrometer (magnetic field 11.72 T), using a Bruker $4 \mathrm{~mm} \mathrm{CP-MAS} \mathrm{probe} \mathrm{at}$ a spinning frequency of $12500 \mathrm{~Hz} .{ }^{11} \mathrm{~B}$ MAS NMR data were acquired for the pristine ISG, as no signal was detected from the altered sample. 
${ }^{29} \mathrm{Si},{ }^{27} \mathrm{Al}$, and ${ }^{1} \mathrm{H}$ were acquired before and after heat treatments at 90 , 150,300 , and $450^{\circ} \mathrm{C}$.

Data availability

The data that support the findings of this study are available from the corresponding author upon reasonable request.

\section{ACKNOWLEDGEMENTS}

This work was supported as part of the Center for Performance and Design of Nuclear Waste Forms and Containers, an Energy Frontier Research Center funded by the U.S. Department of Energy, Office of Science, Basic Energy Sciences under Award \# DESC0016584. The authors are grateful to Nicole Godon (CEA), Géraldine Parisot (CEA), Valentine Laporte (CEA), Laurent Dupuy (Tescan Analytics), Jennifer Renard (CEA), Céline Marcou (CEA), Florence Bruguier (CEA), and Jean-Pierre Mestre (CEA) for technical support and scientific input.

\section{AUTHOR CONTRIBUTIONS}

M.C. was responsible for the experimental analysis and for writing the paper. S.G. supervised the study. M.F. was involved in data interpretation. T.C., M.M., and M.C. performed the solid-state NMR study. All the authors helped on paper editing.

\section{ADDITIONAL INFORMATION}

Supplementary Information accompanies the paper on the npj Materials Degradation website (https://doi.org/10.1038/s41529-018-0036-3).

Competing interests: The authors declare no competing interests.

Publisher's note: Springer Nature remains neutral with regard to jurisdictional claims in published maps and institutional affiliations.

\section{REFERENCES}

1. Gin, S., Jollivet, P., Tribet, M., Peuget, S. \& Schuller, S. Radionuclides containment in nuclear glasses: an overview. Radiochim. Acta 105, 927-959 (2017).

2. Bunker, B. C., Arnold, G. W., Day, D. E. \& Bray, P. J. The effect of molecular structure on borosilicate glass leaching. J. Non Cryst. Solids 87, 226-253 (1986).

3. Sanders, D. M. \& Hench, L. L. Mechanisms of glass corrosion. J. Am. Ceram. Soc. 56, 373-377 (1973).

4. Scholze, H. Chemical durability og glasses. J. Non Cryst. Solids 52, 91-103 (1982).

5. Gin, S. et al. An international initiative on long-term behavior of high-level nuclear waste glass. Mater. Today 16, 243-248 (2013).

6. Hellmann, R. et al. Unifying natural and laboratory chemical weathering with interfacial dissolution-reprecipitation: a study based on the nanometer-scale chemistry of fluid-silicate interfaces. Chem. Geol. 294-295, 203-216 (2012).

7. Geisler, T. et al. Aqueous corrosion of borosilicate glass under acidic conditions: a new corrosion mechanism. J. Non Cryst. Solids 356, 1458-1465 (2010).

8. Gin, S. et al. The controversial role of inter-diffusion in glass alteration. Chem. Geol. 440, 115-123 (2016).

9. Gin, S. et al. Atom-probe tomography, TEM and ToF-SIMS study of borosilicate glass alteration rim: a multiscale approach to investigating rate-limiting mechanisms. Geochim. Cosmochim. Acta 202, 57-76 (2017).

10. Gin, S. et al. Origin and consequences of silicate glass passivation by surface layers. Nat. Commun. 6, 6360 (2015).

11. Collin, M. et al. Structure of international simple glass and properties of passivating layer formed in circumneutral pH conditions. npj Mater. Degrad. 2, Article number 4 (2018).

12. Dove, P. M. The dissolution kinetics of quartz in aqueous mixed cation solutions. Geochim. Cosmochim. Acta 63, 3715-3727 (1999).

13. Dove, P. M. \& Crerar, D. A. Kinetics of quartz dissolution in electrolyte solutions using a hydrothermal mixed flow reactor. Geochim. Cosmochim. Acta 54, 955-969 (1990).

14. Dove, P. M. \& Nix, C. J. The influence of the alkaline earth cations, magnesium, calcium, and barium on the dissolution kinetics of quartz. Geochim. Cosmochim. Acta 61, 3329-3340 (1997).

15. Jollivet, P., Gin, S. \& schumacher, S. Forward dissolution rate of silicate glasses of nuclear interest in clay-equilibrated groundwater. Chem. Geol. 330, 207-217 (2012).

16. Feng, X. \& Pegg, I. L. Effects of salt solutions on glass dissolution. Phys. Chem. Glass. 35, 98-103 (1994).

17. Vienna, J. D., Ryan, J. V., Gin, S. \& Inagaki, Y. Current understanding and remaining challenges in modeling long-term degradation of borosilicate nuclear waste glasses. Int. J. Appl. Glass Sci. 4, 283-294 (2013).

18. Gin, S. Open Scientific Questions about nuclear glass corrosion. Procedia Mater. Sci. 7, 163-171 (2014).
19. Jegou, C., Gin, S. \& Larche, F. Alteration kinetics of a simplified nuclear glass in an aqueous medium: effects of solution chemistry and of protective gel properties on diminishing the alteration rate. J. Nucl. Mater. 280, 216-229 (2000).

20. Angeli, F. et al. Influence of lanthanum on borosilicate glass structure: a multinuclear MAS and MQMAS NMR investigation. J. Non Cryst. Solids 376, 189-198 (2013).

21. Chave, T., Frugier, P., Gin, S. \& Ayral, A. Glass-water interphase reactivity with calcium rich solutions. Geochim. Cosmochim. Acta 75, 4125-4139 (2011).

22. Schneider, J. et al. Qn distribution in stoichiometric silicate glasses: thermodynamic calculations and 29Si high resolution NMR measurements. J. Non Cryst. Solids 325, 164-178 (2003).

23. Angeli, F., Gaillard, M., Jollivet, P. \& Charpentier, T. Influence of glass composition and alteration solution on leached silicate glass structure: a solid-state NMR investigation. Geochim. Cosmochim. Acta 70, 2577-2590 (2006).

24. Quintas, A. et al. NMR study of a rare-earth aluminoborosilicate glass with varying CaO-to-Na2O ratio. Appl. Magn. Reson. 32, 613-634 (2007).

25. Ollier, N., Charpentier, T., Boizot, B., Wallez, G. \& Ghaleb, D. A Raman and MAS NMR study of mixed alkali $\mathrm{Na}-\mathrm{K}$ and $\mathrm{Na}-\mathrm{Li}$ aluminoborosilicate glasses. J. Non Cryst. Solids 341, 26-34 (2004).

26. Neeway, J. J. et al. Low-temperature lithium diffusion in simulated high-level boroaluminosilicate nuclear waste glasses. J. Non Cryst. Solids 405, 83-90 (2014).

27. Neeway, J. J. et al. lon-exchange interdiffusion model with potential application to long-term nuclear waste glass performance. J. Phys. Chem. C. 120, 9374-9384 (2016).

28. Hofmeister, F. Zur lehre von der wirkung der salze. Arch. F. Exp. Pathol. U. Pharmakol. 24, 247-260 (1888).

29. Teppen, B. J. \& Miller, D. M. Hydration energy determines isovalent cation exchange selectivity by clay minerals. Soil Sci. Soc. Am. J. 70, 31 (2006).

30. Hocine, S. et al. How ion condensation occurs at a charged surface: a molecular dynamics investigation of the stern layer for water-silica interfaces. J. Phys. Chem. C. 120, 963-973 (2016).

31. Eisenman, G. Cation selective glass electrodes and their mode of operation. Biophys. J. 2, 259-323 (1962).

32. Eberl, D. D. Alkali cation selectivity and fixation by clay minerals. Clays Clay Miner. 28, 161-172 (1980).

33. Cailleteau, C. et al. Insight into silicate-glass corrosion mechanisms. Nat. Mater. 7, 978-983 (2008).

34. Cailleteau, $\mathrm{Cl}$ et al. Why do certain glasses with a high hissolution rate undergo a low degree of corrosion? J. Phys. Chem. C. 115, 5846-5855 (2011).

35. Gin, S. et al. Dynamics of self-reorganization explains passivation of silicate glasses. Nat. Commun. (2018).

36. Fournier, M. et al. Glass dissolution rate measurement and calculation revisited. J. Nucl. Mater. 476, 140-154 (2016).

37. Fluegel, A. Global model for calculating room-temperature glass density from the composition. J. Am. Ceram. Soc. 90, 2622-2625 (2007).

38. lacovino, K. Glass Density Calc v3.2, http://www.kaylaiacovino.com/tools-forpetrologists/ (2017).

39. Wild, B. et al. pH-dependent control of feldspar dissolution rate by altered surface layers. Chem. Geol. 442, 148-159 (2016).

40. Larsen, F. H. \& Farnan, I. 29Si and 170 (Q)CPMG-MAS solid-state NMR experiments as an optimum approach for half-integer nuclei having long T1 relaxation times. Chem. Phys. Lett. 357, 403-408 (2002).

41. Massiot, D. et al. Modelling one- and two-dimensional solid-state NMR spectra. Magn. Reson. Chem. 40, 70-76 (2002).

42. Salles, F., Bildstein, O., Douillard, J. M., Jullien, M. \& Van Damme, H. Determination of the driving force for the hydration of the swelling clays from computation of the hydration energy of the interlayer cations and the clay layer. J. Phys. Chem. C. 111, 13170-13176 (2007).

43. Rosseinsky, D. R. Electrode potentials and hydration energies. Theor. Correl. Chem. Rev. 65, 467-490 (1965).

Open Access This article is licensed under a Creative Commons Attribution 4.0 International License, which permits use, sharing, adaptation, distribution and reproduction in any medium or format, as long as you give appropriate credit to the original author(s) and the source, provide a link to the Creative Commons license, and indicate if changes were made. The images or other third party material in this article are included in the article's Creative Commons license, unless indicated otherwise in a credit line to the material. If material is not included in the article's Creative Commons license and your intended use is not permitted by statutory regulation or exceeds the permitted use, you will need to obtain permission directly from the copyright holder. To view a copy of this license, visit http://creativecommons. org/licenses/by/4.0/.

(c) The Author(s) 2018 